\title{
Resistance of Tool Steel Processed by Unconventional Forming Technology aga- inst Abrasive Wear
}

\author{
Kateřina Rubešová ${ }^{1}$, Michal Peković ${ }^{1}$, Hana Jirková ${ }^{1}$, David Hradil ${ }^{2}$ \\ ${ }^{1}$ Faculty of Mechanical Engineering, University of West Bohemia in Pilsen. Univerzitní 2732/8, 30100 Pilsen, \\ Czech Republic, EU. E-mail: krubesov@rti.zcu.cz \\ ${ }^{2}$ COMTES FHT a.s., Průmyslová 995, Dobřany, 334 41, Czech Republic, EU, E-mail: david.hradil@comtesfht.cz
}

Materials for parts which are subjected to abrasive wear in service are typically selected on the basis of the microstructure type and hardness. Additional characteristics, such as grain size and the size and morphology of carbides are considered less frequently, although they may prove very important. This article deals with treatment cycles which combine an unconventional forming technique and subsequent heat treatment and explores its impact on abrasive wear resistance in X210Cr12 tool steel. Effects of microstructure refinement prior to and during forming and during heat treatment are described. The forming cycle involved semi-solid processing and was followed by quenching. This sequence refined the initial microstructure and altered the morphology of chromium carbides. The semi-finished products were then cryogenically treated at $-160^{\circ} \mathrm{C}$ for 24 hours and in some cases, subsequently tempered at $300^{\circ} \mathrm{C}$ for 2 hours. Their wear resistance was tested by blasting and the relationship between the treatment and the weight loss in the test was assessed.

Keywords: abrasion wear; wear resistance; carbides; tool steel

\section{Introduction}

One of the most frequent issues in heavy-duty machine parts is abrasive wear, particularly on their functional surfaces. Abrasive wear shortens the life of tools and increases financial costs due to the need for replacement or repair of the affected parts.

Tool steels are one class of materials in which high resistance to abrasive wear is required. High resistance to abrasive wear is typically seen as related to high hardness. Yet, abrasive wear resistance is a complex property. There are several microstructural aspects which can improve wear resistance. The key ones are the morphology, volume fraction and distribution of carbides. Wear resistance can also be improved by altering the phases in the matrix, which may involve martensite [1]. Some other factors come into play as well, such as the grain size and general morphology of the microstructure.

One method of altering the microstructure to improve wear resistance is semi-solid processing which involves partial melting of the material. Its primary use is for high-alloy hypereutectoid tool steels. [2-4]. This technique can eliminate primary sharp-edged chromium carbides, produce very fine microstructures and provide high hardness. Ductility can then be improved by subsequent tempering or by cryogenic treatment and tempering.

In this paper, the relationship between semi-solid process parameters and wear resistance in X210Cr12 hypereutectoid tool steel is explored. Wear testing was carried out with the use of abrasive water jet blasting.

\section{Materials and methods}

$\mathrm{X} 210 \mathrm{Cr} 12$ tool steel was selected as the material for this series of experimental trials. It is a typical member of the hypereutectoid steels group with sharp-edged chromium carbides. As a cold work tool steel, it is used for making punching, shearing and press-forming tools, shaping and crushing tooling and plastic injection or powder moulds. The material's data sheet [5] recommends heat treatment that consists of austenitizing between $940^{\circ} \mathrm{C}$ and $970{ }^{\circ} \mathrm{C}$, oil quenching and final tempering between $100^{\circ} \mathrm{C}$ and $300{ }^{\circ} \mathrm{C}$. Thanks to its chemical composition, its freezing range is wide, making it a good candidate for semi-solid processing (Table 1) [5].

Tab. 1 Chemical composition of the steel under investigation (wt. \%)

\begin{tabular}{|c|c|c|c|c|c|c|}
\hline $\mathrm{C}$ & $\mathrm{Cr}$ & $\mathrm{Mn}$ & $\mathrm{Si}$ & $\mathrm{Ni}$ & $\mathrm{P}$ & $\mathrm{S}$ \\
\hline 1.8 & 12 & 0.3 & 0.35 & $\max 0.5$ & $\max 0.03$ & $\max 0.035$ \\
\hline
\end{tabular}


The material was supplied in annealed condition. It contained large sharp-edged chromium carbides and very fine cementite particles in a ferritic matrix (Fig. 1). Since these carbides are difficult to eliminate, a forming sequence combined with semi-solid processing was chosen for this investigation. High heating temperatures are required for this process. They cause primary chromium carbides to dissolve. For this steel, the appropriate temperatures are between 1225 and $1250^{\circ} \mathrm{C}$. When combined with the right forming sequence and quenching, this process can lead to a very fine microstructure and fine chromium carbides. With its carbide morphology and distribution, this microstructure could provide high wear resistance.

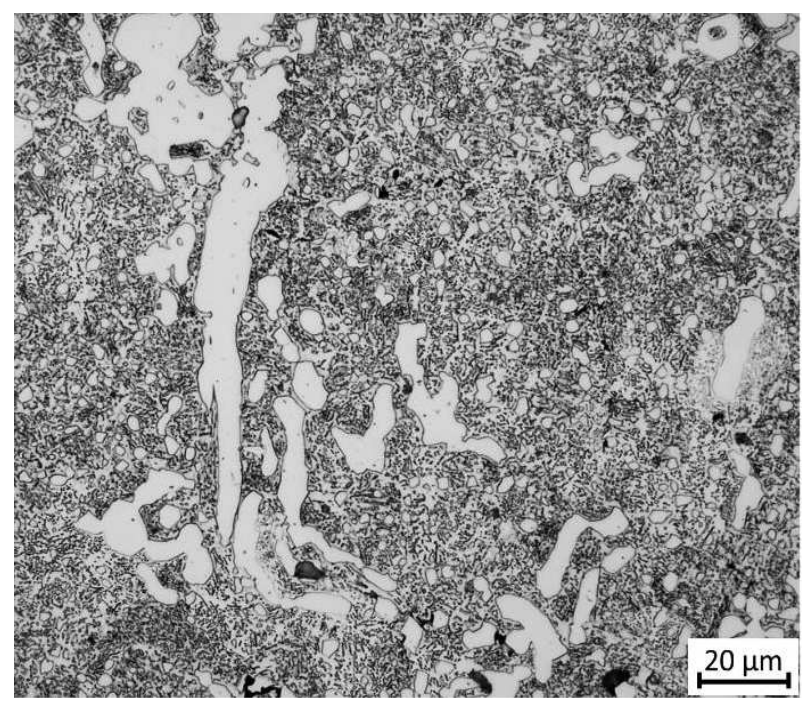

Fig. 1 As-received condition of X210Cr12 steel, light micrograph

Experimental specimens had a $75 \mathrm{~mm}$ diameter and $100 \mathrm{~mm}$ height. The specimens were enclosed in a container of SJ355 low-carbon steel to ensure they can be handled safely when in the partially melted condition. The melting temperature of this steel is higher than that of the tool steel [6-8]. Process cycles described in Table 2 were proposed with a view to explore the impact of the individual process parameters. In the first cycle, the material was heated into the semi-solid state at $1250^{\circ} \mathrm{C}$, held for 60 minutes and then quenched in water at ambient temperature.

In order to reveal the impact of mechanical working, additional cycles that involved hydraulic press forming were carried out. The specimens were heated to $1250^{\circ} \mathrm{C}$, held for 60 minutes and then quenched in water for 35 seconds. After quenching, they were placed in a furnace at $1080^{\circ} \mathrm{C}$ and held for 30 minutes to allow their temperature to homogenize. According to material data sheets, this is the recommended forging temperature for X210Cr12. After removal from the furnace, ten blows alternating upsetting and drawing out were applied to the specimens. After five blows, the workpiece was reheated to $1080^{\circ} \mathrm{C}$. At the end of the forming sequence, the specimen was quenched in water. In the final cycles, cryogenic treatment or cryogenic treatment followed by tempering were added. The purpose was to determine whether these additional operations can further improve wear resistance. The cryogenic temperature was $-160^{\circ} \mathrm{C}$ and the treatment time was 24 hours. Tempering at $300^{\circ} \mathrm{C}$ was performed for 2 hours. For comparison with conventional heat treatment, the as-received (i.e. annealed) material and quenched and tempered material were tested as well.

For all these cycles, the resulting microstructures were studied and the hardness of the material was measured. The microstructures were observed under Olympus light microscope. Vickers hardness was measured using $10 \mathrm{~kg}$ load. Wear resistance was tested by a water jet with abrasive particles.

Tab. 2 Parameters of processing cycles

\begin{tabular}{|c|c|c|c|c|c|c|c|}
\hline $\begin{array}{l}\mathrm{T}\left[{ }^{\circ} \mathrm{C}\right] / \\
\mathrm{t}[\mathrm{min} .]\end{array}$ & $\begin{array}{l}\text { Quenching } \\
\text { medium/ } \\
\mathrm{t}[\mathrm{s}]\end{array}$ & $\begin{array}{l}\mathrm{T}_{\text {forming }} \\
{\left[{ }^{\circ} \mathrm{C}\right] /} \\
\mathrm{t} \text { [min.] }\end{array}$ & Deformation & $\begin{array}{l}\text { Cooling/ } \\
\text { medium }\end{array}$ & $\begin{array}{l}\mathrm{T}_{\text {cryo. }} / \\
\mathrm{t}[\mathrm{hr} .]\end{array}$ & $\begin{array}{l}\mathbf{T}_{\text {tempering }} \\
{\left[{ }^{\circ} \mathrm{C}\right] / \mathrm{t}[\mathrm{hr} .]}\end{array}$ & $\begin{array}{l}\text { HV10 } \\
{[-]}\end{array}$ \\
\hline \multicolumn{7}{|c|}{ Initial condition of X210Cr12 } & 216 \\
\hline $960 / 40$ & Oil $\left(80^{\circ} \mathrm{C}\right)$ & - & - & - & - & $250^{\circ} \mathrm{C} / 2$ & 716 \\
\hline \multirow{4}{*}{$1250 / 60$} & \multirow{4}{*}{ Water } & & No def. & - & - & - & 349 \\
\hline & & \multirow{3}{*}{$1080^{\circ} \mathrm{C} / 30$} & \multirow{3}{*}{ 10-step def. } & \multirow{3}{*}{ Water } & - & - & 770 \\
\hline & & & & & $-160 / 24$ & - & 905 \\
\hline & & & & & $-160 / 24$ & $300 / 2$ & 844 \\
\hline
\end{tabular}

The blasting test was conducted in a water jet cutting machine (WJ2030-2Z-Cobra-PJ60 from the company PTV, spol. s.r.o.). The jet combined the use of a water nozzle and an abrasive-material nozzle. The abrasive particles were ClassicCut 80 garnet-GMA. Each test was performed with 20 grams of abrasive material, for 200 seconds, at a nozzle distance of 100 $\mathrm{mm}$ and using a pressure of $4130 \mathrm{MPa}$ (Fig. 2). The blasting parameters were identical in all the tests. They are listed in Table 3. Materials treated in this fashion are used for parts in which enhanced wear resistance 
is required, such as crusher plates. Therefore, the incidence angle of the abrasive matter should be taken into account. Blasting was therefore performed in a direction perpendicular to the surface under test and at an angle of $30^{\circ}$ to the normal of the surface. Specimens with dimensions of $35 \times 40 \mathrm{~mm}$ were used.
Their weight was from $105 \mathrm{~g}$ to $218 \mathrm{~g}$. Prior to blasting, the surface was ground to a roughness of $0.8 \mathrm{Ra}$. Two specimens were used for each blasting direction. Weight losses were determined using laboratory scales.
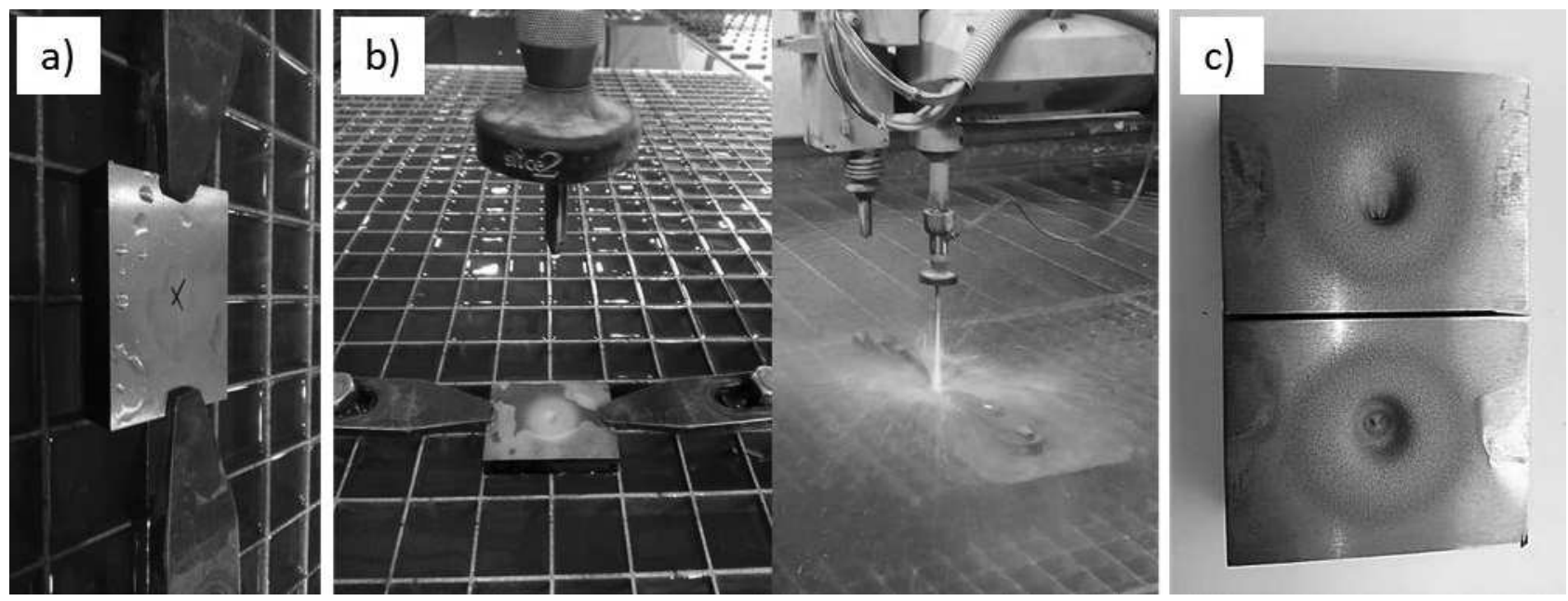

Fig. 2 Blasting process: a) input specimen, b) nozzle setup and blasting, c) specimens after blasting

Tab. 3 Blasting test parameters to determine abrasive wear resistance

\begin{tabular}{|l|c|c|c|c|c|c|c|}
\hline \multicolumn{2}{|c|}{ Nozzle diameter $[\mathrm{mm}]$} & $\begin{array}{c}\text { Distance } \\
{[\mathrm{mm}]}\end{array}$ & $\begin{array}{c}\text { Amount of } \\
\text { abrasive ma- } \\
\text { terial }[\mathrm{g}]\end{array}$ & $\begin{array}{c}\text { Pressure } \\
{[\mathrm{MPa}]}\end{array}$ & $\begin{array}{c}\text { Crater radius } \\
{[\mathrm{mm}]}\end{array}$ & Time $[\mathrm{s}]$ & Angle $\left[^{\circ}\right]$ \\
\hline 0.1 water & 0.9 abr. & 100 & 20 & 4130 & 2.5 & 200 & 90 \\
\hline 0.1 water & 0.9 abr. & 100 & 20 & 4130 & 2.5 & 200 & 30 \\
\hline
\end{tabular}

\section{Results and discussion}

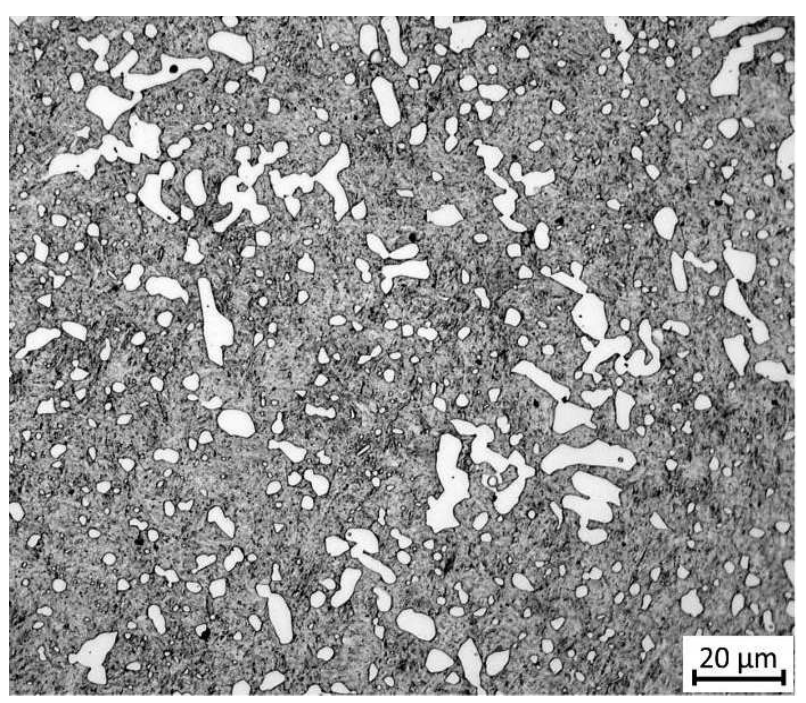

Fig, 3 Quenched and tempered material, light micrograph

The as-received material was in the annealed condition. The microstructure contained large sharp-edged chromium carbides and very fine cementite embedded in a ferritic matrix (Fig. 1). The hardness was 216 HV10. Perpendicular blasting caused a weight loss of $1.73 \mathrm{~g}$. Blasting at $30^{\circ}$ to the normal led to a loss of $1.69 \mathrm{~g}$.

After conventional quenching and tempering, the microstructure consisted of tempered martensite with a fine dispersion of chromium carbides (Fig. 3). In addition, the primary chromium carbides remained present but they were less sharp-edged and were smaller. Since the matrix was not ferritic but martensitic, hardness was much higher: 716 HV10. However, this high hardness failed to translate into abrasive wear resistance. The weight loss after perpendicular blasting was $1.78 \mathrm{~g}$. After blasting at $30^{\circ}$ to the normal, it was $1.61 \mathrm{~g}$.

The $1250^{\circ} \mathrm{C}$ semi-solid processing cycle with a soaking time of 60 minutes, no post-process mechanical working and with subsequent quenching produced a microstructure of polyhedral austenite grains embedded in a ledeburite network. The austenite volume fraction was close to $90 \%$. The network itself was a mixture of austenite and carbides. The material had a hardness of 349 HV 10 (Fig. 4a). In this case, the weight loss was relatively higher due to the large amount of austenite. With the perpendicular nozzle, it was $1.82 \mathrm{~g}$. At $30^{\circ}$ angle to the normal, it was $1.76 \mathrm{~g}$.

After cooling to $1080^{\circ} \mathrm{C}$, ten deformation steps 
caused significant microstructure refinement. The grain size was approximately $5 \mu \mathrm{m}$. Since the material was quenched after cooling, its matrix consisted of martensite and a small amount of untransformed austenite with a fine dispersion of chromium carbides. Secondary chromium carbides smaller than $1 \mu \mathrm{m}$ were uniformly redistributed. This led to a relatively higher hardness value of 770 HV10 (Fig. 4b). Weight losses were smaller than in the as-received material, the quenched and tempered material, as well as the semi-solid-processed material with no post-process deformation. Blasting in the perpendicular direction led to a loss of $1.40 \mathrm{~g}$, whereas the inclined blasting test at $30^{\circ} \mathrm{C}$ resulted in a weight loss of $1.48 \mathrm{~g}$.
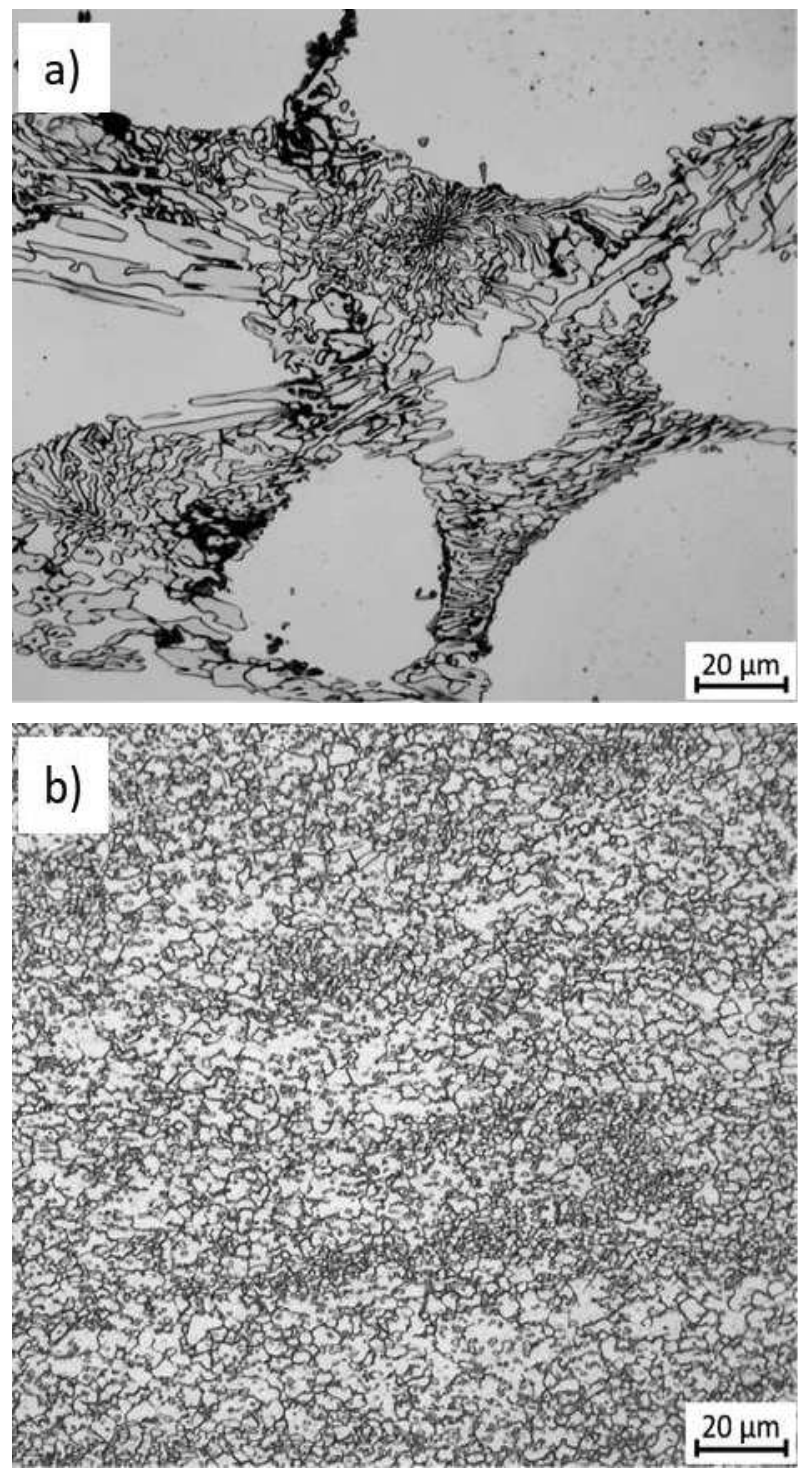

Fig. 4 Microstructures produced by semi-solid processing: a) with no post-process mechanical working, b) with subsequent ten-step deformation; light micrographs

The semi-solid processing cycle with cryogenic treatment led to a higher hardness of 905 HV10. Cryogenic treatment was expected to eliminate some retained austenite by cooling below the Ms and to stabilize martensite in the microstructure which would be accompanied by precipitation of fine and uniform carbides during tempering. The resulting microstructure consisted of fine martensite, uniformly-dispersed chromium carbides and a small amount of retained austenite (Fig. 5a). The weight loss was even less than in the previous cycles. With perpendicular blasting it was $1.33 \mathrm{~g}$; and at $30^{\circ}$ to the normal, it reached $1.42 \mathrm{~g}$.

The last cycle involved semi-solid processing, tenstep deformation, cryogenic treatment and subsequent tempering at $300^{\circ} \mathrm{C}$ for 2 hours. The resulting microstructure showed no substantial differences to the previous cycle which had involved no tempering. However, it was finer and the carbide precipitation induced by tempering was more intensive (Fig $5 b$ ). Tempering led to a lower hardness: 844 HV10. Weight loss was higher than after the cycle without tempering. For the perpendicular direction, it was $1.61 \mathrm{~g}$. With the nozzle at $30^{\circ} \mathrm{C}$ to the normal, it was $1.48 \mathrm{~g}$.
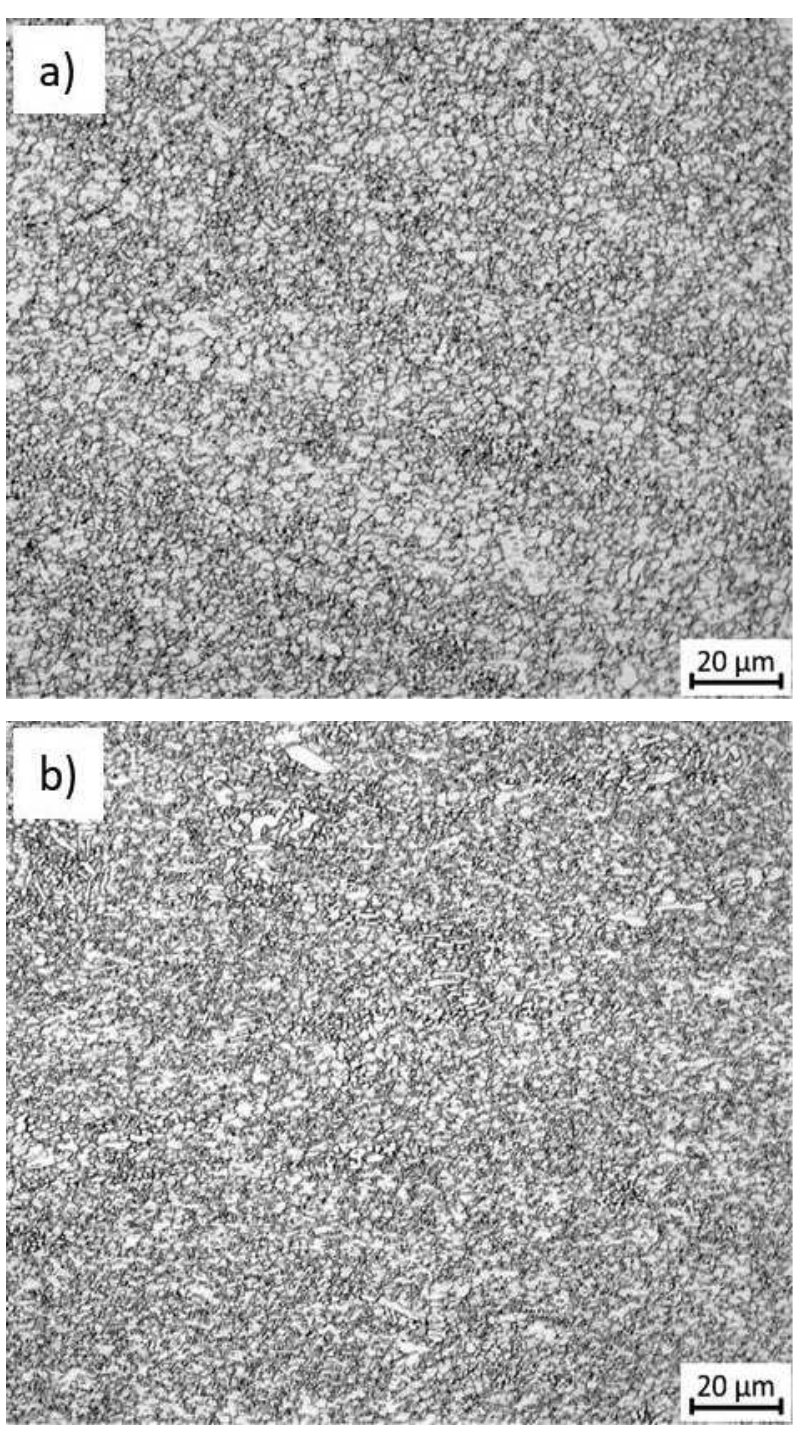

Fig. 5 Microstructures produced by semi-solid processing and mechanical working: a) with subsequent cryogenic treatment, b) with subsequent cryogenic treatment and tempering at $300^{\circ} \mathrm{C} / 2$ hours; light micrographs 
Tab. 4 Blasting test parameters to determine abrasive wear resistance

\begin{tabular}{|c|c|c|c|c|}
\hline \multirow{7}{*}{$90^{\circ}$} & weight loss [g] & \multirow{7}{*}{$30^{\circ}$} & weight loss [g] & treatment \\
\hline & 1.73 & & 1.69 & initial state \\
\hline & 1.78 & & 1.61 & tempered \\
\hline & 1.82 & & 1.76 & without deformation \\
\hline & 1.40 & & 1.48 & 10 def. \\
\hline & 1.33 & & 1.42 & 10 def. - cryogenic \\
\hline & 1.61 & & 1.48 & 10 def. - cryo. and temp. \\
\hline
\end{tabular}

Wear testing clearly showed that the weight loss is directly related to hardness. The highest weight loss $(1.8 \mathrm{~g})$ (Table 4) occurred after the cycle which involved heating at $1250^{\circ} \mathrm{C} / 60$ minutes and quenching in water. In this case, the microstructure consisted of globular austenite and lamellar ledeburite network with a hardness of 349 HV10. Similar values were obtained in the as-received material and the quenched and tempered material, where the weight loss was approximately $1.75 \mathrm{~g}$ (Table 4). They were lower due to larger carbides and the presence of martensite. Greater differences were found in the semi-solid processed and mechanically worked material which had a much finer microstructure with a martensitic matrix and fine chromium carbides. The smallest weight loss was found after semi-solid processing, ten-step deformation and cryogenic treatment: $1.33 \mathrm{~g}$ (Table 4). It was due to stronger precipitation promoted by cryogenic treatment and due to less retained austenite (RA) in the structure.

Larger weight loss was caused by perpendicular blasting than by blasting at $30^{\circ}$ to the normal (Fig. 6). That having been said, the weight losses for both directions showed the same trends for the different processing cycles.

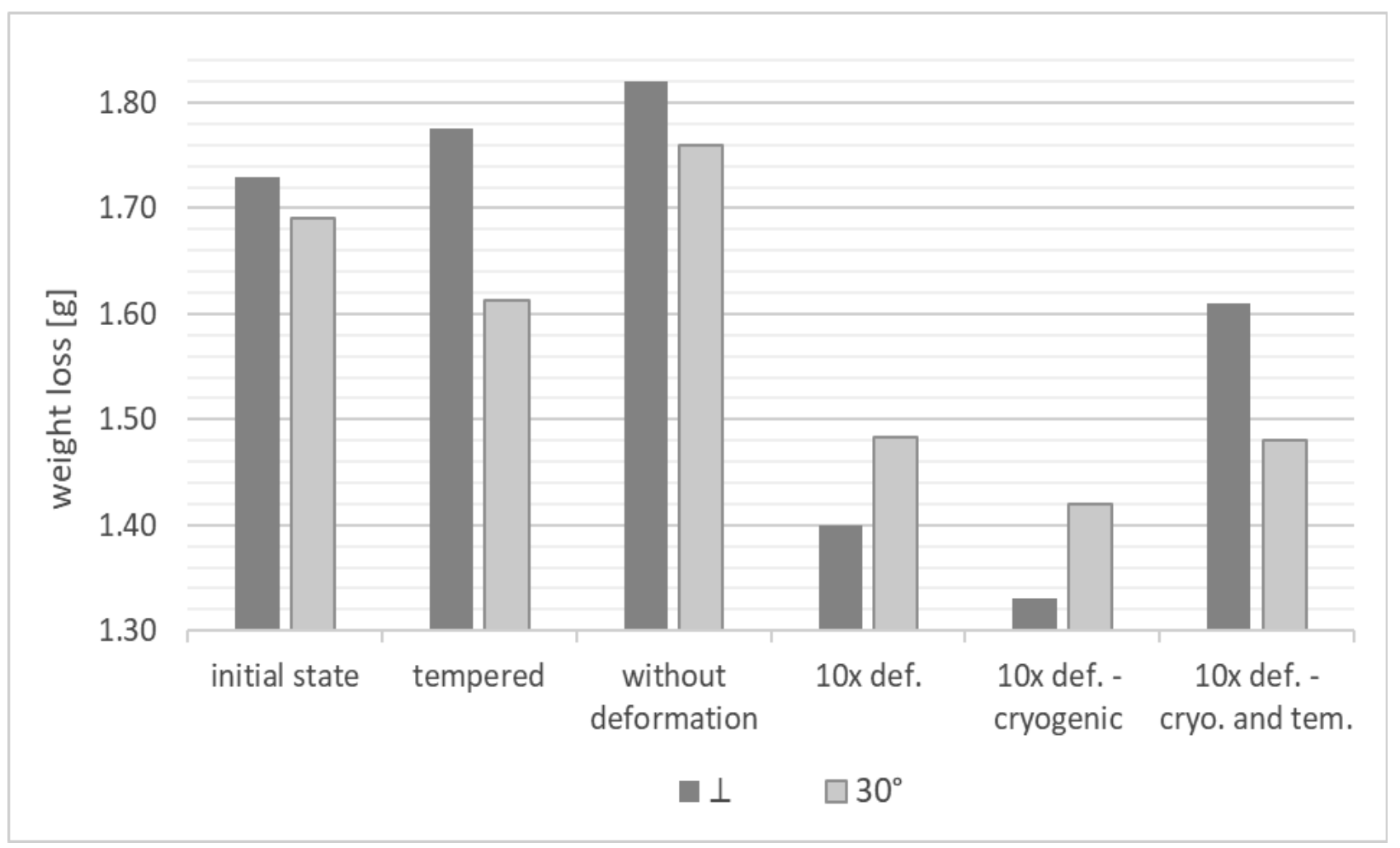

Fig. 6 Weight loss caused by blasting vs. nozzle angle

\section{Conclusion}

Experimental investigation was carried out to explore the wear resistance of $\mathrm{X} 210 \mathrm{Cr} 12$ tool steels treated by various cycles. The tests involved blasting with abrasive material. Primary chromium carbides were eliminated from the microstructure by treatment cycles which involved bringing the material into the semi-solid state and combinations with cryogenic treatment and tempering.

Semi-solid processing followed by forming in a hydraulic press led to fine martensitic microstructures with a uniform carbide dispersion which were free from sharp-edged chromium carbides. Their hardness 
was $770 \mathrm{HV} 10$. The cycle with cryogenic treatment led to an even higher hardness: 907 HV10.

Microstructural changes were reflected strongly in the blasting test. The largest weight loss, $1.82 \mathrm{~g}$ was found for microstructures with polyhedral austenite grain in lamellar carbide-based networks which had been produced by semi-solid processing without postprocess mechanical working. The cycle with mechanical working led to considerable grain refinement to a size of approx. $5 \mathrm{um}$, as well as to transformation of austenite to martensite and precipitation of very fine carbides, which resulting in a lower weight loss: $1.4 \mathrm{~g}$. This tendency was then strengthened by an additional cryogenic treatment operation. The cycle led to the lowest weight loss: $1.33 \mathrm{~g}$.

\section{Acknowledgement}

This research was funded by the Technology Agency of the Czech Republic under the project TJ02000182 „Improvement of wear resistance of tool steels by a combination of semi-solid treatment with subsequent hot forming and deep cryogenic treatment".

\section{References}

[1] SAPATE, S.G.; CHOPDE, A.D.; NIMBALKAR, P.M.; CHANDARKAR, D.M. (2007). Effect of microsturcture on slury abrasion response of En-31 steel. Mater. Des. 2007, 28, 1923-1927.

[2] RUBEŠOVÁ, K., M. PEKOVIC and $\mathrm{H}$. JIRKOVÁ. (2017). Innovative process to eliminate ledeburite network in tool steel. Manufacturing Technology. 2017, 17(6). ISSN 12132489.

[3] JIRKOVÁ, H., K. RUBEŠOVÁ, K. OPATOVÁ, M. PEKOVIĆ and B. MAŠEK.
(2017). Effect of heating temperature during semi-solid processing on structure of X210CR12 steel. Acta Metallurgica Slovaca [online]. 2017, 23(3). ISSN 13381156. Available from: doi:10.12776/ams.v23i3.969.

[4] JIRKOVÁ, H., RUBEŠOVÁ, K., KONOPÍK, P., OPATOVÁ, K. (2008). Effect of the Parameters of Semi-Solid Processing on the Elimination of Sharp-Edged Primary Chromium Carbides from Tool Steel. METALS, 2018, roč. 8, č. 9, s. 1-15. ISSN: 2075-4701. MATTHEWS, J.R., MATTHEWS, W.R. Successful Scientific Writing: A Step-by-Step Guide for the Biological and Medical Sciences. Cambridge: Cambridge University Press, 2008

[5] D3 Cold Work Steel | 1.2080 | X210Cr12 | SKD1 - Otai Special Steel. 4140 Plate, 440C, M2 HSS - Tool Steel \& Alloy Steel - Otai Special Steel [online]. Dostupné z: http://www.astmsteel.com/product/d3cold-work-steel-1-2080-x210cr12-skd1/. [cite: 12.02.2021]

[6] SONG TENBO, KANG YONGLIN, ZHAO AIMIN (2008). Semi-solid rolling process of steel strips, Journal of Materials processing Technology 198 (2008), 291-299

[7] A. RASSILI, H. V. ATKINSON: A review of steel thixoforming. Trans. Nonferrous Met. Soc. China 20(2010) s1048-s1054.

[8] W. PUTTGEN, B. HALLSTEDT, W. BLECK, P.J. UGGOWITZER (2007). On the microstructure formation in chromium steels rapidly cooled from the semi-solid state, Acta Materialia 55 (2007) 1033-1042 